\title{
ECOS DA CULTURA POLÍTICA BRASILEIRA: O PROGRAMA DE CIÊNCIAS SOCIAIS NO ESTADO DA BAHIA - COLUMBIA UNIVERSITY - COMO VETOR PARA UMA MODERNIZAÇÃO CONSERVADORA BAIANA.
}

João Diogenes Ferreira dos Santos ${ }^{1}$

\section{RESUMO}

O presente artigo é fruto dos resultados da pesquisa, que foi um recorte do projeto de pesquisa vinculado ao Museu Pedagógico da Universidade Estadual do Sudoeste da Bahia, denominado: Revistando o Programa das Ciências Sociais no Estado da Bahia - Columbia Universiy. Neste caso, o objetivo deste artigo é analisar o contexto histórico do citado Projeto, entendendo o mesmo como o caminho inicial da trajetória do desenvolvimento econômico da Bahia, que se ancorou na concepção política, marcada pelos traços autoritários. Esse Programa foi criado em 1949, por meio de um convênio entre a então Secretaria de Educação e Saúde do Estado da Bahia, sob o comando de Anísio Teixeira, e a Columbia University. Nesse contexto, as elites políticas baianas conceberam um projeto modernizador de inspiração liberal, que se iniciou no governo de Octávio Mangabeira (1947-1951). Desta forma, o propósito em estudar o Projeto Columbia e seu contexto é entender a trajetória de modernização baiana, articulada a uma concepção política conservadora das classes dominantes, cuja essência foi associar o desenvolvimento econômico à manutenção da ordem, com a finalidade de garantir a permanência do mandonismo, da relação de favor e do autoritarismo.

Palavras-chaves: Projeto Columbia University; Cultura Política e Modernização Conservadora.

\section{ABSTRCT}

This article is an outcome of the results of an investigation that was conducted within the research project linked to the Pedagogical Museum of the State University of the Southwest of Bahia, entitled: Revisiting the Social Sciences Program in the State of Bahia - Columbia Universiy. In this case, the aim of this paper is to analyze the historical context of that Project, regarded as the initial path in way of economic development in Bahia, which was founded on the political conception, marked by authoritarian features. That Program was created in 1949, through the concord between the State of Bahia Health and Education Secretary, under the command of Anísio Teixeira, and Columbia University. Within that context, the Bahian political elites conceived a modernizing project of neoliberal inspiration, which started in the government of Octávio Mangabeira (1947-1951). Thus, the goal in studying the Columbia Project and its context is to understand the trajectory of modernization in Bahia, related with a conservative political conception of dominant classes, whose essence was to associate economic development to order preservation, aim to ensure a permanence of the mandonism, the favoring relationships, and the authoritarianism.

Key-words: Columbia University Project; Political Culture and Conservative Modernization. 
Nas décadas de 30, 40 e 50 do século XX, o Brasil passou pelo seu processo industrial tardio em relação aos países centrais do capitalismo. Em decorrência do golpe militar de 1930, liderado por Getúlio Vargas (1930 a 1945)², chamado por vários autores de "Revolução de 30", assinalou a transição para um período de efervescência econômica e mudanças políticas, sociais e culturais. Trata-se de um processo de industrialização e urbanização promovido pelo Estado e pela burguesia.

Assim, após o golpe, o Estado assumiu o processo de modernização do país, promovendo a infraestrutura urbana e a indústria nacional. A intervenção estatal, organizando, planejando e criando as condições básicas (malhas rodoviárias, portos, sistemas elétricos, aeroportos, entre outras), proporcionou a instalação de uma indústria integrada e, por conseguinte, o país deixou de ser mero agroexportador para internacionalizar sua economia.

No entanto, esse desenvolvimento econômico, na esteira de Florestan Fernandes (2006), se amalgamou ao "mandonismo oligárquico" e implementou um "modelo autocrático burguês" para iniciar a modernização tecnológica e a aceleração econômica. Do ponto de vista analítico do autor, o "modelo autocrático" configura-se enquanto instrumento da burguesia brasileira para se manter e exercer a dominação. Tal modelo está relacionado ao poder exclusivo de uma classe "que se impõe sem rebuços de cima para baixo, recorrendo a quaisquer meios para prevalecer, erigindo-se a si mesmo em fonte de sua própria legitimidade e convertendo [em uma situação limite] o Estado nacional democrático em instrumento puro e simples de uma ditadura de classe preventiva" (FERNANDES, 2006, p.346).

O exercício desse poder brutal e violento só ocorreu, plenamente, com a ditadura militar instaurada em 1964. Neste sentido, Cohn (2001, p.404), tentando explicar a chave interpretativa acima, observa que a "autocracia de que fala Florestan não é sinônimo de autoritarismo - pois este corresponde a uma forma de exercício do poder e não da sua organização - e nem mesmo se confunde com ditadura, embora não a exclua. Tem mais a ver com a concentração exclusiva e privatista do poder."

Com base neste conceito, Fernandes aponta "triplas condições vantajosas" para burguesia no processo de modernização no Brasil, que são:

$1^{\circ}$ ) para estabelecer uma associação mais íntima com o capitalismo financeiro internacional; $2^{\circ}$ ) para reprimir, pela violência ou pela intimidação, qualquer ameaça operária ou popular de subversão da ordem (mesmo como uma "revolução democrático-burguesa"); $3^{\circ}$ ) para transformar o Estado em instrumento exclusivo do poder burguês, tanto no plano econômico quanto nos planos social e político (FENANDES, 2006, p.256).

Sob esta ótica, pode-se invocar Ianni (2004, p. 218), que, ao refletir sobre o golpe de 30, afirma que "A revolução de 30 teve um cunho contra-revolucionário, no sentido de se fazer face ao ascenso político de forças populares "[...] foi nesse contexto que Antônio Carlos [governador de Minas Gerais] fez a famosa declaração: Façamos a revolução, antes que o povo faça"3

Assim, o Estado assumiu a questão social por meio de mecanismos ideológicos e repressivos para "esvaziá-las do conteúdo político" (PAOLI, 1989). O atendimento as revindicações populares não poderiam conflitar com os interesses das novas frações da classe dominante que ascendiam ao poder e com o processo de industrialização e urbanização inaugurado no país. 
Com essa característica peculiar da história brasileira, o crescimento interno não se deu de forma homogênea nas regiões brasileiras e o dinamismo econômico ficou centrado no eixo Rio de Janeiro - São Paulo, o que determinou um fluxo migratório para esses centros industriais e de expansão urbana, nos quais os trabalhadores buscavam melhores condições de vida, nesses locais.

Neste cenário histórico, a Bahia, segundo Risério (2004), ficou de fora do projeto industrializante brasileiro iniciado pelo governo Vargas. $\mathrm{O}$ autor assinala que:

A política econômica de Getúlio Vargas não beneficiou a classe dominante baiana, como demonstrou o banqueiro e político Clemente Mariani, no estudo-projeto, "Análise do Problema Baiano". "Madrasta" foi, aliás, a expressão escolhida por Mariani para definir, da ótica da elite baiana, a arregimentação político-militar que colocou Vargas no poder (RISÉRIO, 2004, 245).

A Bahia vivenciava, nas primeiras décadas do século $\mathrm{XX}$, uma aparente contradição, possuía potencial econômico para se desenvolver industrialmente, mas se encontrava estagnada economicamente e sem prestigio político junto ao governo central ${ }^{4}$. Uma região que, historicamente, teve seu apogeu no início da colonização, com a produção de açúcar, e na segunda metade do século de XIX, com "[...] multitude de engenhos de açúcar e rapadura, engenhos de aguardente, fábricas de tecidos, fábricas de sela e arreios, fábricas de velas, de beneficiamento de produtos alimentícios, de charutos, bancos e uma companhia de seguros" (OLIVEIRA, 2003, p.28). Esse fenômeno do atraso e da paralisia no processo de industrialização ficou denominado por "enigma baiano". Sobre o "enigma baiano" Almeida e Pina (2009, p. 60) ressaltam:

O governador [Otávio Mangabeira] assumiu a hipótese de um "enigma baiano", deflagrando um processo de enfrentamento do atraso pautado numa iniciativa nova: o estudo do enigma e o levantamento de soluções. Com essa iniciativa, o governo já dava pistas de que o problema do atraso não só tinha alcançado foro público, mas que seu enfrentamento se daria em novas bases.

Na busca de decifrar esse "enigma baiano", a problemática do não desenvolvimento regional, alguns estudiosos buscaram entender as razões porque a Bahia não se inseria no processo de industrialização, em curso no país ${ }^{5}$.

Dias Tavares (1987, p. 34), em História da Bahia, explicita esse quadro de atraso e miséria em que se encontrava a Bahia:

esta é uma das maiores frustrações baianas. Para identificar e explicitar os motivos complexos e múltiplos desse atraso em relação aos estados do sul é possível observar que começam nas condições socioeconômicas do estado da Bahia, na continuidade do complexo contraditório trabalhoassalariado e trabalho semi-escravo e na manutenção da grande propriedade da terra. Continua-se esta análise, observando a falta de capitais industriais e o predomínio de capitais comerciais com a velha prática de agiotagem. Também existiram outros fatores: uso de energia a vapor, quando já existia energia elétrica; teares e fuso antiquados; caldeiras, rolos-moendas e turbinas centrífugas velhas e defeituosas; falta de mão de obra treinada; vias de comunicações deficientes; mercado interno pobre e sem dinheiro. No caso das fábricas de tecidos, soma-se também à distância em que se encontravam dos centros produtores de algodão. 
Francisco de Oliveira (2003, p. 29), dentro de outra concepção teórica, em certa medida, comunga com essa análise, quando diz:

\begin{abstract}
quais são as raízes, as causas desse fracasso? Em primeiro lugar, a ligação umbilical com o setor exportador, e, em segundo lugar, a sustentação da demanda interna criada pela dinâmica das próprias exportações. Breve, é a forma da divisão social do trabalho e das relações de produção da própria indústria que travam seu desenvolvimento. Ao cair à procura externa do produto clássico da exportação baiana, o açúcar, numa agonia que começa no século XIX [...].
\end{abstract}

Valendo-nos das contribuições citadas aqui, o presente artigo trata de analisar, de forma panorâmica, o contexto histórico do Projeto Columbia University, entendendo esse Projeto como o caminho inicial da trajetória do desenvolvimento econômico da Bahia, que se ancorou na concepção política, marcada pelos traços autoritários e por práticas de violência que encontram um estuário perverso nos efeitos de uma modernização conservadora, referenciada por Florestan Fernandes ${ }^{6}$.

No final da década de 40, em 1947, com o término do Estado Novo, no processo de redemocratização, foi vitorioso na eleição para governador do Estado da Bahia, Octávio Mangabeira $^{7}$ do Partido da União Democrática Nacional-UDN. Risério (2004) salienta que o governo de Otávio Mangabeira (1947-1951) cria o Plano de Ação Econômica, na tentativa de inserir a Bahia no estágio industrial nacional.

O governo de Otavio Mangabeira cerca-se de um secretariado, formado por intelectuais baianos, entre eles, encontrava-se Anísio Teixeira, como responsável pela Secretaria de Educação e Saúde. O importantíssimo intelectual possuía a preocupação de desvendar a situação vivida pelos baianos, seja na capital, como no interior. Para isto, buscou auxílio junto aos estudiosos para entender a realidade baiana (CONSORTE, 2005).

No intuito de realizar essa empreitada de entender a realidade sócio-políticoeconômica da Bahia, Anísio Teixeira, à frente da Secretaria de Educação e Saúde, encontrou as condições para firmar o convênio com a University Columbia, com o objetivo de criar o Programa de Pesquisas Sociais na Bahia.

Sobre esse Convênio, o Diário Oficial do Estado da Bahia, de 02 de julho de 1949, publicou o seguinte texto:

Exposição de motivos de 15 de junho de 1949.

Senhor Governador.

1. No interesse de se aparelhar com os elementos informativos necessários ao planejamento do Sistema de Educação, esta Secretaria entrou em entendimento com a Columbia University, U.S.A, através de seu Departamento de Antropologia para a realização, sob a orientação de Mr Charles Wagls do mesmo Departamento, de pesquisas e estudos do meio físico social e econômico de comunidades típicas das várias regiões do Estado.

2. Segundo os entendimentos havidos, essas pesquizas e estudos sejam realizados em colaboração financeira e técnica com esta Secretaria, que destinará para esse fim até CR $\$ 200.000,00$ (duzentos mil cruzeiros), enquanto a contribuição da Columbia University será de cerca de quatro mil dólares, moedas americanas.

3. Com estes esclarecimentos, venho submeter o assunto à alta consideração de V.Excia., solicitando-lhe se digne de, no caso de aprovar 
a iniciativa desta Secretaria, autorizar o empenho da quantia correspondente a sua contribuição financeira, pela verba 306-4-I-16 do orçamento vigente.

Reitero à V. Excia., neste ensejo, os protestos de meu grande apreço e respeitosa estima. (ass.) Anísio Spinola Teixeira - Secretário.

Ass. V.Excia. Dr Octávio Mangabeira. M.D.Governador do Estado da Bahia. Autorizo. Bahia, 15 de junho de 1949.

Otávio Mangabeira. ${ }^{8}$

O convênio celebrado entre o estado da Bahia e a Universidade Columbia fazia parte dos esforços americanos para se conhecer as comunidades pobres dos países latinoamericanos, trazia, portanto benefícios para ambos os lados interessados nos estudos. Para coordenar o projeto foram escolhidos Thales de Azevedo (Universidade da Bahia), Charles Wagley (Universidade Columbia) e Costa Pinto (Universidade do Brasil) (CONSORTE, 2005).

O projeto Columbia, como ficou conhecido, funcionou da seguinte forma: pequenas comunidades foram escolhidas para serem estudadas por doutorandos vindos da universidade americana. Consorte (2005, p.65) sublinha que:

um estudo preliminar sobre as zonas ecológicas do Estado da Bahia foi realizada pela equipe de dirigente do Projeto (Thales, Wagley e Costa Pinto) e, a partir dela, foram selecionadas três áreas para o estudo - o Recôncavo Açucareiro, a Chapada Diamantina e o Sertão. Em cada uma delas foi escolhida uma comunidade representativa do Brasil arcaico ou tradicional, aquela que era considerado em via de desparecimento e outra, representativa do Brasil moderno, aquele que vinha surgindo a partir do desenvolvimento ensejado pelo fim da segunda guerra mundial e que servia como contraponto à primeira. A influência de "os dois brasis" de Jacques Lambert, parece evidente da formulação do projeto.

Menezes (2011, p.69) contribui com essa descrição, quando afirma que:

a regionalização do Estado deveria obedecer a uma racionalidade para sua definição [...]. O estado da Bahia foi dividido em seis zonas ecológicas: Recôncavo, Sertão do Nordeste, Floresta do Sul, Planalto Central, vale do São Francisco e Planalto Ocidental. Tomando inicialmente o Recôncavo, o Sertão do Nordeste e o Planalto Central, foram realizados estudos em duas localidades de cada uma delas, procurando captar a tensão tradição/decadência $\mathrm{e}$ isolamento $\mathrm{x}$ prosperidade/ progresso e modernidade.

A princípio, os resultados das pesquisas seriam fornecidos para o governo baiano. Acreditava-se na época que comparando o modo de vida das comunidades atrasadas com as regiões mais desenvolvidas seria possível estabelecer, quais as melhores vias para a modernização do estado. Havia então uma crença em todo o país que era necessário acabar com o Brasil arcaico para que enfim pudesse emergir a nação moderna, industrial e desenvolvida (CONSORTE, 2005).

Menezes (2011) novamente contribui com nossa análise, ao relacionar os propósitos do Projeto Columbia que deveriam subsidiar os programas da então Secretaria de Educação e Saúde: 
1. Adquirir um conhecimento da sociedade e da cultura rurais em três zonas ecológico-culturais do Estado da Bahia;

2. Determinar o efeito de três diferentes cenários ecológicos sobre padrões de cultura luso-brasileiros [...] que se desenvolveram nessa área rural do Brasil durante os últimos 400 anos;

3. Determinar as mudanças na sociedade e cultura que ocorreram em cada zona dentro dos últimos anos sob o impacto de novas formas de economia, de novas técnicas, de novas ideias e de facilidades de transporte mais modernos;

4. Determinar a dinâmica dessas mudanças em cada zona e as diferenças e semelhanças do processo de uma zona para outra;

5. Determinar que aspectos da sociedade e da cultura atuais, assim como das tendências de mudanças, devem ser considerados, tendo em vista planejar e administrar eficientemente programas educacionais e sanitários na região.

6.

Dentro desta perspectiva de entender o Projeto Columbia, Medeiros (2009, p.97) apresenta, por meio do coordenador do Projeto na Bahia, o método utilizado nas pesquisas:

Thales de Azevedo (1968) esclarece que o método escolhido foi o de "estudos de comunidades", em que a cultura de uma pequena sociedade, considerada representativa dos modos de vida de uma sociedade regional ou nacional, é analisada por meio de instrumentos teóricos da hodierna Antropologia Social.

No caso, o planejamento da investigação, a abordagem metodológica dos problemas e as técnicas de campo foram basicamente etnográficas, mas, combinados com os da Sociologia. A cultura foi, em consequência, descrita e interpretada como uma unidade funcional e dinâmica a partir da história social e da ecologia de cada comunidade.

O Projeto Columbia durou do ano de 1949 a 1953 e possibilitou inúmeros estudos sobre a Bahia, na tentativa de entender a realidade baiana. ${ }^{9}$ Para dar suporte a essa política, conforme determinava a Constituição Baiana de 1947, o governo Mangabeira criou a Fundação para o Desenvolvimento da Ciência na Bahia, idealizada por Anísio Teixeira. A criação dessa primeira Fundação de fomento foi no dia 13 de dezembro de 1950, conforme publicação do Diário Oficial do Estado da Bahia, de 17 de dezembro de 1950:

Lei $\mathrm{n}^{\circ} 347$, de 13 de Dezembro de 1950.

Cria a Fundação para o Desenvolvimento da Ciência na Bahia e lhe proporciona recursos para a respectiva manutenção.

O governador do Estado da Bahia.

Faço saber que a Assembleia Legislativa decreta e eu sanciono a seguinte lei:

Artigo $1^{\circ}$ - É criada a Fundação para o Desenvolvimento da Ciência na Bahia, com autonomia financeira nos termos desta lei.

Artigo $2^{\circ}$ - A Fundação destina-se a coordenar, estimular e assistir a pesquisa e o trabalho científico em todos os seus ramos, concorrendo para o desenvolvimento da Ciência por todos os meios a seu alcance.

Artigo $3^{\circ}$ - A Fundação será administrada por um Conselho Diretor composto de sete membros, escolhidos dentre pessoas ilibadas reputação que se dediquem a estudos e pesquizas científicas.

Parágrafo Único - O primeiro Conselho Diretor será nomeado livremente pelo Governador do Estado. 
Artigo $4^{\circ}$ - Ao Conselho Diretor cabe elaborar o Estatuto da Fundação e providenciar a aquisição de sua personalidade jurídica.

Artigo $5^{\circ}$ - Os membros do Conselho Diretor exercerão o mandato por seis anos.

Parágrafo Único - De três em três anos haverá, alternadamente, renovação de três e quatro membros, mediante indicação em lista tríplice organizada pelo Conselho Diretor e enviada ao Governador do Estado para escolha e nomeação.

Artigo $6^{\circ}$ - Para manutenção da Fundação, o governo do Estado entregará a seu Conselho Diretor metade da percentagem prevista no Artigo 28 do Ato de Disposições Constitucionais Transitórias ${ }^{10}$, que recolherá em quotas mensais, a um estabelecimento de crédito desta cidade, sem prejuízo de outros recursos que lhe venham a ser atribuídos pelo governo, ou que a Fundação venha a obter por outros meios. O Conselho Diretor fica obrigado a prestar contas anualmente ao Secretário de Educação e Saúde do Estado da Bahia.

Artigo $7^{\circ}$ - Extinguindo-se a Fundação seus bens e direitos passarão ao domínio do Estado.

Artigo $8^{\circ}$ - Revogam-se as disposições em contrário.

Palácio do Governo do Estado da Bahia, em 13 de dezembro de 1950.

Octávio Mangabeira

Rogério Gordilho de Farias

Archimedes Pereira Guimarães. ${ }^{11}$

A Fundação para o Desenvolvimento da Ciência na Bahia foi responsável pelo convênio entre o governo do Estado e a Universidade Columbia, criando as condições de viabilizar o acordo entre as partes, como assinala o registro da Revista Técnica da Fundação (1958, p.150):

O primeiro encargo da Fundação para Desenvolvimento da Ciência na Bahia, por ato do governador do Estado da Bahia, de 23 de janeiro de 1951, foi o cumprimento do convênio firmado entre o governo do Estado e a Columbia University, realizado em 15 de julho de 1949, para realização de pesquisa no planejamento da educação, saúde pública e na administração no Estado, coordenado por Charles Waglez (representando a Columbia University) e Thales de Azevedo (representando o Governo do Estado).

O governo garantiu os recursos do Tesouro do Estado para execução do Projeto Columbia, que visava, conforme mencionado acima, entender os aspectos históricos, geográficos, demográficos, econômicos e culturais da realidade baiana, em especial os municípios das regiões do Recôncavo, Sertão e Chapada Diamantina.

O Relatório Financeiro e de Despesas do Programa de Pesquisas Sociais do Estado da Bahia - Columbia University ${ }^{12}$, referentes aos anos de 1949 a 1953, assinado pelo professor Talhes de Azevedo, e datado de 22 de abril de 1953, registra as despensas realizadas durante as pesquisas, relacionando, grosso modo, as quantias utilizadas em cada item. Os itens foram divididos pelo professor Thales de Azevedo da seguinte forma:

- Instalação e Equipamentos;

- Viagens (combustível, conserto da camionete, passagens de avião, trem e ônibus, dentro do Estado da Bahia); 
- Pessoal (diárias, gratificações, despesas no trabalho de campo) [neste item há relação dos pesquisadores e quantia de recurso destinado a cada um];

- Serviço fotográfico e Miscelânea;

- Livros adquiridos;

- Despesas com as remessa de dólares.

Também nesse documento pode-se verificar as fontes dos recursos empregados no Programa de Pesquisas Sociais na Bahia: os provenientes das organizações norteamericanas (Social Science Rearch Council, Viking Fund, Werner Green Foundation), Dougherty Fund) e os liberados pelo governo do Estado, por meio da Secretaria Estadual de Educação e Saúde.

O governo, como contra partida, garantiu ao Projeto, pesquisadores e técnicos, deslocando-os de órgãos da administração para a Fundação de Desenvolvimento da Ciência na Bahia, de acordo com a publicação do Diário Oficial do Estado da Bahia, de 26 de janeiro de 1951.

Por a disposição.

Da Fundação para o Desenvolvimento da Ciência, sem prejuízo das vantagens dos seus cargos, os funcionários da Secretaria de Educação e Saúde:

Thales Olimpio Góes de Azevedo - Médico, classe M.

Josildeth da Silva Gomes - Professora, classe B.

Terezinha Pires de Souza - Professora, classe B

Maria Carmelita Junqueira - Assistente, extranumerário mensalista.

Sônia Maria d'Oliveira Santos - Auxiliar de Escritório interna, classe A.

Mario Martins de Oliveira -Desenhista, classe I.

Francisco de Souza Paixão - Auxiliar de Portaria, classe A.

Angelino lago de Fonseca - Motorista, classe C. ${ }^{13}$

Portanto, pode-se inferir que o governo de Otávio Mangabeira possibilitou a gêneses do processo de modernização na Bahia, criando condições políticas, econômicas e ideológicas para esse processo. A criação da Fundação para o Desenvolvimento da Ciência na Bahia, em 1950, é um exemplo dessa ação, pois esse órgão deveria fomentar a pesquisa e a inovação tecnológica, elementos essenciais para o início de um processo de desenvolvimento, que aconteceu na década de 50, pelos mesmos ditames que ocorreu no eixo Rio de Janeiro - São Paulo, sob a batuta da "modernização conservadora".

O desenvolvimento econômico, político e social, ocorrido no Brasil, promoveu uma "abissal desigualdade social" (OLIVEIRA, 1999). Nesses termos, a expansão capitalista, no Brasil, aconteceu, aludindo-se ao termo de Florestan Fernandes (2006), pela via da "modernização conservadora", marcada pela junção de uma modernização industrial e o autoritarismo político, e a não participação das classes trabalhadoras nesse processo.

Para o autor, na expansão capitalista brasileira não houve confronto estrutural entre a burguesia e a oligarquia - o velho e o novo se fundiram. A burguesia não entrou em conflito com a aristocracia agrária - e, neste caso, tratou-se de uma espécie de "revolução dentro da ordem" -, mas favoreceu-se dos aspectos vantajosos da antiga estrutura. Com isso, a burguesia ajustou-se à tradição, erigindo mudanças graduais e um processo de modernização. Por sua vez, "os grupos oligárquicos realizaram acordos e firmaram compromisso, modernizando-se e se aburguesando, pois os interesses locais dos senhores tornaram-se interesses nacionais" (FERNANDES, op.cit, p. 55). 
Francisco de Oliveira (2003, p.60), em seu artigo clássico em que critica a concepção dualista da sociedade brasileira, enriquece esta linha de raciocínio, ao afirmar que "a expansão do capitalismo no Brasil se dá introduzindo relações novas no arcaico e reproduzindo relações arcaicas no novo [...]". A combinação desses aspectos contraditórios compõe o motor que dinamiza a economia e serve de alicerce à sociedade. Assim sendo, a "modernização conservadora" se expressa nos avanços econômicos, amalgamados aos traços da cultura política, em que o autoritarismo, mandonismo e personalismo são marcas desse processo. Ou seja, para o autor, com base em Florestan Fernandes, a "modernização conservadora", ocorrida no Brasil, foi sem revolução burguesa, em que o caráter produtivo do atraso serviu de base para a expansão capitalista.

Para Dantas (2004), a noção de "modernização conservadora" foi desenvolvida por Moore Jr, a partir das evidencias históricas da modernização implantada em países, como: Alemanha, Itália e Japão. Essa noção significa "uma transformação pelo alto" e "uma revolução vinda de cima", em que:

o processo de mudança social, politicamente orientado, é conduzido por uma autoridade política que, compensando a fraqueza relativa de uma burguesia incapaz de hegemonia, reprime ou se antecipa à ação de grupos contestatórios, compatibilizando interesses e valores de elites modernizantes e de grupos sociais conservadores, deslocados da velha ordem (DANTAS, op. cit. p. 25).

Portanto, pode-se afirmar que a mesma expressão, tanto adotada e adaptada por Dantas Neto como utilizada por Francisco de Oliveira, converge com o conceito de "revolução passiva" de Antônio Gramsci ${ }^{14}$ e com as reflexões de Florestan Fernandes.

A indústria nacional, associada ao capital internacional, dinamizou os outros setores da economia. No entanto, a vitalidade econômica não melhorou as condições de vida da população de baixo poder aquisitivo, ao contrário, intensificou o processo de empobrecimento desse contingente populacional, agravando a questão social.

Neste cenário, a Bahia, a partir da década de 50, inseriu-se na política desenvolvimentista do governo federal, com propósito de modernizar sua economia e adaptar o projeto local ao nacional, porém sem alterar a peculiaridade política configurada pelos traços da cultura política (DANTAS NETO, 2004).

Sobre este processo, Elias Darzé Filho ${ }^{15}$ sublinha que:

o processo de industrialização da economia baiana começou efetivamente por causa da política federal de integração da economia nacional via "desconcentração industrial". A dinâmica do sistema capitalista induzia a intensificação do processo de acumulação proveniente da industrialização brasileira, concentrada na região sudeste. A estratégia do governo federal era promover o crescimento de outras áreas do país que fossem mais bem dotadas de recursos naturais, mão de obra barata, localização e outras vantagens competitivas, estimulando a atração de indústrias potenciais. Nesse sentido, ocorreram inversões maciças da esfera federal na região Nordeste, especificamente na Bahia, quer seja através de incentivos financeiros e fiscais para a instalação de indústrias de base, vinculadas ao processo de integração produtiva com o Centro-Sul, quer seja através de investimentos em educação, saúde e, especialmente, infraestrutura com a construção de portos, rodovias, ferrovias, suprimento de energia e água, etc. 
Por Salvador ser o centro administrativo, político e financeiro do estado, associado à descoberta do petróleo e do gás no Recôncavo, transformou a Região Metropolitana de Salvador - RMS - em uma área do território nacional, que se adequou perfeitamente à política federal de desconcentração da produção industrial.

O Estado, nas esferas federal e estadual, edificou as condições econômicas, sociais, políticas e ideológicas para o processo de modernização. Com a instalação da Petrobrás $(1953)^{16}$, os vários ramos da elite baiana conciliaram seus interesses, com propósito de industrializar o Estado, sobretudo a capital e a região do recôncavo (DANTAS NETO, 2003).

Sob a mesma ótica, Francisco de Oliveira, em seu estudo sobre as relações entre as classes e suas identidades na Bahia, na década 70, marcada pelo apogeu do desenvolvimento econômico baiano, particularmente em Salvador, expõe que

[...] na vaga do movimento nacionalista dos 1950, o Estado brasileiro tomara a si, depois de rejeitadas as continuadas ofertas ao capital internacional, a tarefa de fornecer petróleo à estrutura industrial, que avança significativamente. Esta "socialização" da poupança nacional é, em si mesma, uma forma de imposição da hegemonia das novas burguesias industriais do Centro-Sul [do país]. A Petrobrás escolhe a bacia sedimentar do Recôncavo Baiano para iniciar a pesquisa sistemática e, logo, a exploração do petróleo. Na metade dos anos 50, ela já está explorando petróleo e instala uma pequena refinaria [Refinaria Landulfo Alves - RLAM] no município de Mataripe. Durante três décadas, o Recôncavo Baiano será o único produtor nacional de petróleo, chegando a produzir um quarto das necessidades nacionais (OLIVEIRA, 2003, p.42).

Desse modo, a Petrobrás impulsionou a industrialização na Bahia, principalmente na região Metropolitana. A empresa, segundo Francisco de Oliveira (2003), investiu no período entre 1955 e 1959, uma vultosa soma na economia do Estado, destinada a investimentos na infraestrutura da Refinaria e nos salários dos empregados. Além disto, cresceu a receita do Estado por meio dos royalties, impostos fiscais derivados dos gastos da Petrobrás, salários e atividades econômicas, surgidas em consequência da própria expansão industrial.

Tais investimentos, somados ao aumento da receita do Estado, produziram as condições propícias para iniciar o processo de industrialização, o desenvolvimento do comércio, a construção de infraestrutura (estradas, portos, etc.) capaz de atender às demandas dessa realidade. Também, ocorreram mudanças na configuração espacial da capital baiana, mediante a expansão da malha urbana, a fim de atender o fluxo migratório atraído pela abertura de um novo mercado trabalho (ANDRADE, 2000).

De acordo com Andrade (2000, p.141), "os investimentos privilegiados dos governos federal e estadual, a disponibilidade da força de trabalho em abundância e a ausência de movimentos de trabalhadores, amparados por sindicatos fortes e atuantes", configuraram-se em condições favoráveis para a modernização econômica na Bahia.

O desenvolvimento da economia baiana não veio acompanhado de um desenvolvimento social. Ao contrário, com a modernização da economia e o aumento da receita do estado a concentração de renda também aumentou, acentuando ainda mais as desigualdades social e econômica. O capitalismo implantado não gerou um mercado consumidor em via de fato, como ocorreu nas economias dos países industrializados. $\mathrm{O}$ crescimento foi atrofiado, convivendo com práticas de trabalho pré-capitalista. Neste 
processo, a industrialização não criou uma classe operária consciente e atuante, e não abriu possibilidades de ascensão social para as classes mais baixas (OLIVEIRA, 2003).

Neste processo, o Estado e a burguesia utilizaram os meios repressivos violentos para conter e silenciar as greves, as manifestações, as reivindicações e os protestos dos trabalhadores considerados, de acordo com acepção de Florestan, "inimigos comuns das classes dominantes", que poderiam ameaçar os interesses e estabilidade das classes dominantes.

Portanto, como já se analisou acima, à luz das contribuições de Florestan Fernandes, as classes dominantes efetivaram um modelo econômico, ancorado "na autocracia burguesa de transformação capitalista", tanto no eixo Rio de Janeiro e São Paulo, inicialmente, a partir de 1930, e como na Bahia, nos anos 50, consolidaram seu processo de desenvolvimento econômico e urbanístico.

Sob essa mesma ótica, pode-se, novamente, afirmar que o Programa de Ciências Sociais no Estado da Bahia- University Columbia - foi uma tentativa de decifrar o "enigma baiano" (MEDEIROS, 2009), em que as pesquisas sobre a realidade baiana seriam subsídios para intervenção estatal na criação das condições de um desenvolvimento industrial na Bahia $^{17}$.

\section{Referências}

ANDRADE, Eliziário. Nova Ofensiva do Capital sobre o Trabalho. Salvador: Editora UCSal, 2000.

CONSORTE, J. GOMES. "Itinerário de uma pesquisadora: sucessos e percalços". In:MAGALHÃES, Lívia Diana Rocha e CASIMIRO, Ana Palmira Bittencourt Santos (Orgs.). Memória e Trajetória de Pesquisa. Campo Grande. Ed. UNIDERP, 2005

DIAS, Luiz Henrique Tavares. História da Bahia. EDUFBA: Salvador, 1987.

DANTAS NETO, Paulo Fábio. “Surf” nas ondas do tempo: do Carlismo histórico ao carlismo pós-carlista." In: Caderno Centro de Recursos Humanos - CRH - n 39 julho/dezembro. UFBA, 2003.

DANTAS NETO, Paulo Fábio. Tradição, autocracia e carisma: a política de Antonio Carlos Magalhães na modernização da Bahia (1954-1974). Tese de Doutorado em Ciências Sociais do Instituto Universitário de Pesquisas do Rio de Janeiro - IUPERJ. Rio de Janeiro, 2004. Mimeo.

DARZÉ FILHO, Elias. A Problemática da verticalização com adensamento e articulação da estrutura industrial da Bahia. www.desenbahia.ba.gov.br. Acessado, em 29 de novembro de 2011.

FERNANDES, Florestan. A Revolução Burguesa no Brasil: ensaio de interpretação sociológica. $5^{\circ}$ edição. São Paulo: Globo, 2006.

GRAMSCI, Antônio. Cadernos do Cáceres. Volume 1. $2^{\circ}$ edição. Rio de Janeiro: Civilização Brasileira, 2001.

IANNI, Octavio. Pensamento Social do Brasil. São Paulo: EDUSC, 2004. 
MEDEIROS, Ruy. "O Programa de Pesquisas Sociais do Estado da Bahia- Universidade de Columbia: O seu Contexto". In Revista Quaestio, Sorocaba, SP, v. 11, n. 1, p. 89-110, maio de 2009.

MENEZES, Jaci Maria Ferraz de. "Anísio Teixeira, a Bahia e a Educação: desenvolvimento e modernidade em discussão". In: ALMEIDA, José Rubens Mascarenhas de; MAGALHÃES, Lívia Diana Rocha e BERTONI, Luci Mara (orgs). As Redes Científicas e o desenvolvimento da pesquisa: perspectivas multidisciplinares. São Carlos: Pedro e João Editores, 2011.

MIRANDA, Edimê Gomes e ALVES, Virgínia Santos. "Vitória da Conquista: da Redemocratização (1945) às Sucessões Municipais de 1950 a 1954." In: AGUIAR, Edinalva Padre (org). Política: o Poder em Disputa - Vitória da Conquista e Região. Série Memória Conquistense. Vitória da Conquista: Edições UESB, 1999.

OLIVEIRA, Francisco de e PAOLI, Maria Célia. Os Sentidos da Democracia: política do dissenso e a harmonia global. Petrópolis: Vozes; Brasília: NEDIC, 1999.

OLIVEIRA, Francisco de. O Elo Perdido: classe e identidade de classe na Bahia. São Paulo: Editora Fundação Perseu Abramo, 2003.

PAOLI, Maria Célia. "Trabalhadores e Cidadania: experiência do mundo público na história do Brasil moderno.” In: Estudos Avançados. São Paulo, USP, vol.3, p. 44-66, 1989.

REVISTA TÉCNICA DA FUNDAÇÃO DE DESENVOLVIMENTO DA CIÊNCIA NA BAHIA, Salvador: Fundação de Desenvolvimento da Ciência na Bahia, 1958.

RISÉRIO, Antônio. Uma História da Cidade da Bahia. 2 Ed. Rio de Janeiro: Versal Editores, 2004.

SILVA, Antônia Almeida e PINA, Maria Cristina Dantas. "Educar para enriquecer: o liberal desenvolvimentismo, o projeto tecnocrático e a educação pública na Bahia (19401970)". In: Revista HISTEDBR On-line, Campinas, n.36, p. 57-69, dez.2009.

\section{Notas}

\footnotetext{
1 Doutor em Ciências Sociais, professor do Programa de Pós-Graduação em Memória, Linguagem e Sociedade da Universidade Estadual do Sudoeste da Bahia e pesquisador do Museu Pedagógico.

${ }^{2}$ O chamado período Vargas (1930 a 1945) foi formado por três fases. A primeira compreendeu o governo provisório, de 1930 a 1934. Já a segunda, por ocasião da promulgação da Constituição de 1934, denominada de período constitucional, Getúlio Vargas foi eleito presidente constitucional (1934 a 1937). E a última se deu pelo golpe de Estado, ocorrido em 1937, que manteve Vargas a frente da Presidência até 1945.

${ }^{3}$ Antonio Carlos Ribeiro de Andrade (1926-1930) era o então governador de Minas Gerais, na ocasião do Golpe de 30. O governo de Minas Gerais apoiou militarmente o movimento tenentista, contribuindo, assim, com a destituição do presidente Washington Luís (1926-1930) e, por seu turno, a ascensão de Getúlio Vargas à Presidência da República.

${ }^{4}$ O governo provisório da República (1930-1934) nomeou o interventor, um jovem tenente cearense, de 26 anos, Juracy Magalhães para governar a Bahia (1930-1937). Getúlio Vargas não escolheu nem uma liderança local, foi buscar uma pessoa de fora do estado.

5 Sobre o enigma baiano, Medeiros (2009, p. 94) analisa que "Otávio Mangabeira, para caracterizar o atraso da Bahia apesar de suas potencialidades, adotou a expressão 'enigma baiano'. O problema da involução
} 
econômica da Bahia merecera menção de alguns autores e persistiu como objeto de análise por muito tempo: Como consta nas Referências, Clemente Mariani (1977) dele tratou, assim como Rômulo Almeida (1977), Manoel Pinto de Aguiar (1977) e Luis Henrique Dias Tavares (1966). Foi debate que se prolongou até a década de 1960."

${ }^{6}$ Explicaremos este conceito de Florestan Fernandes, posteriormente.

7 Otávio Mangabeira nasceu em Salvador em 1886, e faleceu no Rio de Janeiro em 1960, era engenheiro civil, jornalista, professor e diplomata. Sua carreira política iniciou como vereador de Salvador, em 1908. Foi deputado, obteve seu primeiro mandato em 1911, e permaneceu no mandato, após vencer algumas eleições, até 1926. Logo após a posse de Washington Luís na presidência da República (1926 a 1930), foi empossado ministro das Relações Exteriores. Em 1930, por apoiar Júlio Prestes para presidência, foi afastado do ministério, preso e exilado, sendo anistiado e retornando ao Brasil, em 1934. Foi eleito para Câmara Federal, aliando-se à oposição a Vargas. Ainda na Câmara, Mangabeira se opôs às medidas repressivas decretadas por Vargas. No Estado Novo (1937-1945) perde seu mandato parlamentar, por conta do fechamento do Congresso. Foi preso em março de 1938 por participar de uma conspiração contra o governo. Em 1945, filia-se à União Democrática Nacional (UDN), partido que formava a oposição liberal ao Estado Novo (TAVARES, 1987). No ano de 1946, retorna à Câmara Federal, como deputado constituinte pela Bahia. As eleições estaduais ocorreram em janeiro de 1957, sendo eleito o Otavio Mangabeira, e tomou posse como governador do Estado da Bahia, em 10 de abril de 1947 (MIRANDA e ALVES, 1999).

${ }^{8}$ Trecho retirado no Diário Oficial do Estado da Bahia, de 02 de julho de 1949, encontrado no arquivo da Biblioteca Pública do Estado da Bahia, conhecida como Biblioteca Central dos Barris, situada na cidade de Salvador-BA.

9 O trabalho de Medeiros (2009), citado nas referências bibliográficas deste artigo, apresenta a lista de estudos relacionados ao Projeto Columbia.

${ }^{10}$ O Artigo 28 do Ato de Disposições Constitucionais e Transitórias da Constituição do Estado da Bahia de 1947 determina que: “o Estado, a partir do exercício de 1948 e por prazo não inferior a dez anos, acrescerá, a todos os impostos um adicional de meio por cento, destinado a, juntamente com outros recursos que a lei determinar e cuja aplicação regulará, integrar o fundo para pesquisas científicas".

${ }^{11}$ Trecho retirado no Diário Oficial do Estado da Bahia, de 17 de dezembro de 1950, encontrado no arquivo da Biblioteca Pública do Estado da Bahia, conhecida como Biblioteca Central dos Barris.

${ }^{12}$ Este documento encontra-se no arquivo particular da professora Maria Brandão, filha de Tales de Azevedo. Há uma cópia desse documento no arquivo do Museu Pedagógico/UESB.

13 Trecho retirado no Diário Oficial do Estado da Bahia, de 17 de 26 de janeiro de 1951, encontrado no arquivo da Biblioteca Pública do Estado da Bahia.

${ }^{14}$ Antônio Gramsci, ao analisar a formação e o desenvolvimento da nação e do Estado moderno na Itália Risorgimento -, ampliou o conceito de "revolução passiva" criado por Vincenzo Cuoco. Como bem esclarece Gramsci (2001, p.209-210): "Vincenzo Cuoco chamou de revolução passiva a revolução ocorrida na Itália, como conseqüência imediata das guerras napoleônicas. O conceito de revolução passiva me parece exato não só para a Itália, mas também para os outros países que modernizaram o Estado através de uma série de reformas ou de guerras nacionais, sem passar pela revolução política tipo radical-jacobino", ou seja, "uma revolução sem revolução" (Idem).

${ }^{15}$ Cf. www. desenbahia.ba.gov.br. Acessado, em 29 de novembro de 2011.

${ }^{16}$ Além da Petrobrás (1953), o governo de Getúlio Vargas (1951-1954) criou outras empresas estatais para dinamizar o processo de industrialização do país, como Banco de Desenvolvimento Econômico - BNDE, Companhia Siderúrgica Nacional (CNS), Companhia de Ácalis -CNA, ente outras

${ }^{17}$ Rui Medeiro (2009, p.105) afirma que "há dificuldades para o estudo do Programa de Estudos Sociais e do convênio com a Universidade de Colúmbia, pois há pesquisas cujos relatórios não foram publicados e, ao que se sabe, existem; e por isso é necessário trabalho de busca em arquivos, novas pesquisas bibliográficas, entrevistas, e buscas na própria Universidade de Colúmbia”.

Recebido em out/2013

Aprovado em out/2013 